\title{
Preoperative Ultrasonography Assessment of Vocal Cord Movement During Thyroid and Parathyroid Surgery
}

\author{
Mayilvaganan Sabaretnam • Pooja Ramakant • \\ Deepak T. Abraham • M. J. Paul
}

Published online: 25 January 2013

(c) Société Internationale de Chirurgie 2013

We read with interest the article "Preoperative ultrasonography assessment of vocal cord movement during thyroid and parathyroid surgery" by Cheng et al. [1]. We congratulate the authors on using a noninvasive modality for evaluating vocal cords preoperatively with no added cost or time. It was a patient-friendly initiative in a resource-constrained environment. Patients with vocal cord palsy may be asymptomatic.

Indirect laryngoscopy is not adequate in all cases. If it is performed routinely, it becomes costly, as do visits to outpatient clinics. There is also patient discomfort to be considered as it is an invasive procedure. ENT surgeons are not widely available; and even if available, these patients are not a priority. The cost incurred, the discomfort for the patient, and the physician's expertise are issues associated with performing regular fiberoptic bronchoscopy. The question of attending surgeons performing indirect laryngoscopy in terms of medicolegal purposes continues to be considered by many surgical societies. If the same logistics are adopted for ultrasonography, the question arises whether it would be more prudent to have the vocal cord examined by radiologists. We have a few queries related to the present study [1-6].

Nonrecurrent laryngeal nerves are rare [2]. Did the Y sign done for evaluation increase the time taken to perform ultrasonography (USG)? Did the authors use USG for performing guided fine-needle aspiration cytology? Were the vocal cords evaluated postoperatively with USG? If yes, then what was the sensitivity and specificity of USG postoperatively [4]? Was pulsed Doppler used to quantify the tissue displacement velocity in the vibrating vocal fold section [3]? Did the authors perform the Valsalva maneuver to adduct the vocal cords? Did the severe sniffing result in displacement of the probe, thereby causing difficulty when performing USG?

\section{References}

1. Cheng SP, Lee JJ, Liu TP et al (2012) Preoperative ultrasonography assessment of vocal cord movement during thyroid and parathyroid surgery. World J Surg 36:2509-2515. doi:10.1007/s 00268-012-1674-1

2. Yetisir F, Salman AE, Ciftçi B et al (2012) Efficacy of ultrasonography in identification of non-recurrent laryngeal nerve. Int J Surg 10:506-509

3. Dedecjus M, Adamczewski Z, Brzeziński J et al (2010) Real-time, high-resolution ultrasonography of the vocal folds: a prospective pilot study in patients before and after thyroidectomy. Langenbecks Arch Surg 395:859-864

4. Sidhu S, Stanton R, Shahidi S et al (2001) Initial experience of vocal cord evaluation using grey-scale, real-time, B-mode ultrasound. ANZ J Surg 71:737-739

5. Yeung P, Erskine C, Mathews P et al (1999) Voice changes and thyroid surgery: is pre-operative indirect laryngoscopy necessary? Aust N Z J Surg 69:632-634

6. Schlosser K, Zeuner M, Wagner M et al (2007) Laryngoscopy in thyroid surgery-essential standard or unnecessary routine? Surgery 142:858-864; discussion 864 . Erratum in: Surgery (2008) $143: 302$

M. Sabaretnam ( $₫)$ · P. Ramakant · D. T. Abraham .

M. J. Paul

Endocrine Surgery Department, Christian Medical College,

Vellore, India

e-mail: drretnam@gmail.com 